\title{
LTP in hippocampal area CAl is induced by burst stimulation over a broad frequency range centered around delta
}

\author{
Lawrence M. Grover, ${ }^{1,3}$ Eunyoung Kim, ${ }^{1}$ Jennifer D. Cooke, ${ }^{1}$ and William R. Holmes ${ }^{2}$ \\ ${ }^{1}$ Department of Pharmacology, Physiology and Toxicology, Marshall University, School of Medicine, Huntington, West Virginia \\ 25755, USA; ${ }^{2}$ Neuroscience Program, Department of Biological Sciences, Ohio University, Athens, Ohio 45701, USA
}

\begin{abstract}
Long-term potentiation (LTP) is typically studied using either continuous high-frequency stimulation or theta burst stimulation. Previous studies emphasized the physiological relevance of theta frequency; however, synchronized hippocampal activity occurs over a broader frequency range. We therefore tested burst stimulation at intervals from $100 \mathrm{msec}$ to $20 \mathrm{sec}(10 \mathrm{~Hz}$ to $0.05 \mathrm{~Hz})$. LTP at Schaffer collateral-CAl synapses was obtained at intervals from $100 \mathrm{msec}$ to $5 \mathrm{sec}$, with maximal LTP at 350-500 msec (2-3 Hz, delta frequency). In addition, a short-duration potentiation was present over the entire range of burst intervals. We found that $N$-methyl-D-aspartic acid (NMDA) receptors were more important for LTP induction by burst stimulation, but L-type calcium channels were more important for LTP induction by continuous high-frequency stimulation. NMDA receptors were even more critical for short-duration potentiation than they were for LTP. We also compared repeated burst stimulation with a single primed burst. In contrast to results from repeated burst stimulation, primed burst potentiation was greater when a 200-msec interval (theta frequency) was used, and a 500-msec interval was ineffective. Whole-cell recordings of postsynaptic membrane potential during burst stimulation revealed two factors that may determine the interval dependence of LTP. First, excitatory postsynaptic potentials facilitated across bursts at 500-msec intervals but not 200-msec or 1-sec intervals. Second, synaptic inhibition was suppressed by burst stimulation at intervals between $200 \mathrm{msec}$ and $1 \mathrm{sec}$. Our data show that CAl synapses are more broadly tuned for potentiation than previously appreciated.
\end{abstract}

Long-term potentiation (LTP) is used as a model for studying synaptic events during learning and memory (Bliss and Collingridge 1993; Morris 2003; Lynch 2004). At most synapses, LTP is triggered by postsynaptic $\mathrm{Ca}^{2+}$ influx through $\mathrm{N}$-methyl-D-aspartic acid (NMDA) glutamate receptors (Collingridge et al. 1983; Harris et al. 1984; Herron et al. 1986) and, under some conditions, through L-type voltage-gated $\mathrm{Ca}^{2+}$ channels (Grover and Teyler 1990, 1994; Morgan and Teyler 1999). LTP was discovered in the dentate gyrus (Bliss and Lomo 1973) following several seconds of 10-100 Hz stimulation of the perforant path. Since then, many LTP studies have used similar long, high-frequency stimulation (HFS) protocols, most typically $100 \mathrm{~Hz}, 1 \mathrm{sec}$ (Bliss and Collingridge 1993). Although effective, HFS does not resemble physiological patterns of activity (Albensi et al. 2007). Patterned stimulation resembling physiological activity, in particular theta burst stimulation, is also effective for LTP induction (Larson et al. 1986; Staubli and Lynch 1987; Capocchi et al. 1992; Nguyen and Kandel 1997). Theta burst stimulation consists of short bursts (4-5 stimuli at $100 \mathrm{~Hz}$ ) repeated at $5 \mathrm{~Hz}$, which lies within the hippocampal theta frequency range (4-12 Hz) (Bland 1986; Buzsáki 2002). Primed burst stimulation, another form of patterned stimulation, involves delivery of a priming stimulus followed by a single short burst (Larson and Lynch 1986; Rose and Dunwiddie 1986). The temporal requirements for primed burst LTP are quite precise (Diamond et al. 1988; Greenstein et al. 1988; Larson and Lynch 1989): Intervals less than $140 \mathrm{msec}$ or greater than $200 \mathrm{msec}$ are ineffective.

The mechanisms underlying theta frequency-dependent LTP have been studied primarily using the primed burst protocol (Larson and Lynch 1986, 1988, 1989; Pacelli et al. 1989; Davies

\footnotetext{
${ }^{3}$ Corresponding author.
}

E-mail grover@marshall.edu; fax (304) 696-7381.

Article is online at http://www.learnmem.org/cgi/doi/10.1101//m.1179109. and Collingridge 1996). Activation of $\mathrm{GABA}_{\mathrm{B}}$ autoreceptors during the priming stimulus suppresses GABA release during the following burst (Davies et al. 1990; Lambert and Wilson 1994; Olpe et al. 1994), allowing greater postsynaptic depolarization (Larson and Lynch 1986; Pacelli et al. 1989) and more effective NMDA receptor activation (Davies and Collingridge 1996). Consequently, temporal requirements for primed burst potentiation match the time course of $\mathrm{GABA}_{\mathrm{B}}$ autoreceptor-mediated suppression of GABA release (Davies et al. 1990; Davies and Collingridge 1993; Mott et al. 1993).

Besides theta, hippocampal activity is observed at other frequencies, notably sharp waves (0.01-5 Hz) (Buzsáki 1986, 1989; Suzuki and Smith 1987) and low-frequency oscillations ( $\leq 1 \mathrm{~Hz}$ ) (Wolansky et al. 2006; Moroni et al. 2007). These lower frequencies dominate during slow wave sleep (Buzsáki 1986; Suzuki and Smith 1987; Wolansky et al. 2006; Moroni et al. 2007), and contribute to hippocampal memory processing (Buzsáki 1989; Pennartz et al. 2002). While synchronized population activity over frequencies from $<1 \mathrm{~Hz}$ to $12 \mathrm{~Hz}$ is associated with hippocampal memory function, previous LTP studies have focused on theta. We therefore investigated burst stimulation at frequencies from $0.05 \mathrm{~Hz}$ to $10 \mathrm{~Hz}$. We found that CA1 synapses potentiate to some degree over this entire range and that maximal potentiation occurs around delta frequency rather than theta.

\section{Results}

Field excitatory postsynaptic potential potentiation (fEPSP) after burst stimulation

Burst stimulation in standard artificial cerebrospinal fluid

We assessed LTP induced by burst stimulation of Schaffer collateral/commissural afferents in area CA1. After placement of 
stimulating and recording electrodes into stratum radiatum, an initial input-output curve was constructed by stimulating at intensities ranging from $1 \mathrm{~V}$ up to the intensity that yielded a field excitatory postsynaptic potential (fEPSP) of maximal slope. For each slice, the test stimulation intensity was chosen as the lowest level of stimulation voltage that evoked a discernible population spike (positive deflection superimposed on the negative fEPSP). Test stimulation intensity averaged $3.9 \pm 0.1 \mathrm{~V}$, producing a fEPSP with a slope of $-1.7 \pm 0.09 \mathrm{~V} / \mathrm{s}(44.6 \% \pm 2.3 \%$ of the maximal fEPSP slope). There were no significant differences among the groups we examined for stimulation intensity (one-way ANOVA, $P$ $=0.50)$, fEPSP slope in $\mathrm{V} / \mathrm{s}(P=0.12)$, or fEPSP slope as percentage of maximal slope $(P=0.75)$.

We tested nine groups of slices with burst stimulation at intervals ranging from none (continuous $100-\mathrm{Hz} \mathrm{HFS}$ ) up to 20 sec. For all burst stimulation conditions, the total number of stimuli delivered was held constant at 80. A 15-min baseline recording period preceded burst stimulation, and slices that failed to show stable fEPSP slopes during this period were excluded from further analysis. One group of slices received continuous $100-\mathrm{Hz}$ tetanization (80 stimuli delivered over $800 \mathrm{msec}$ at $10-\mathrm{msec}$ intervals), and the remaining groups received a series of 20 bursts, separated by intervals of $100 \mathrm{msec}$ to $20 \mathrm{sec}$, with each burst containing four stimuli at $100 \mathrm{~Hz}$. While LTP was consistently observed at all burst intervals between $100 \mathrm{msec}$ and $5 \mathrm{sec}$, inspection of the time courses of potentiation following burst stimulation (Fig. 1) indicated substantial differences in both the final, stable level of LTP at the end of the post-tetanus recording period and the level of potentiation during the initial portion of the post-tetanus recording period.

Slices tetanized in standard artificial cerebrospinofluid (ACSF) showed greatest LTP following burst stimulation at the 350- and 500 -msec intervals $(53.0 \% \pm 13.3 \%$ and $52.2 \% \pm 10.8 \%, n=10$ and 12, respectively; see Figs. 1 and 4B, below). The 200-msec (theta) interval was almost as effective, producing a mean increase in fEPSP slope of $40.5 \% \pm 6.8 \%(n=12)$. Somewhat less LTP was obtained with the $100-\mathrm{msec}(32.3 \% \pm 11.9 \%, n=10)$ and 1 -sec $(33.6 \% \pm 7.3 \%, n=11)$ burst intervals. Continuous $100-\mathrm{Hz}$ tetanization $(24.7 \% \pm 7.0 \%, n=11)$ and 5 -sec burst interval stimulation $(24.7 \% \pm 8.0 \%, n=9)$ produced even less LTP, although LTP was still consistently observed. Burst intervals of 10 and $20 \mathrm{sec}(n=10$ and 8$)$ were largely ineffective for LTP induction, although both intervals were still capable of triggering a small initial potentiation. A one-way ANOVA revealed significant differences among the nine conditions examined $(P<0.02)$. Post-hoc comparisons (Tukey HSD test) indicated significant differences $(P<0.05)$ between the 350-msec and 20 -sec burst intervals and between the 500-msec and 20 -sec burst intervals. The remaining pairwise comparisons failed to reach significance. Overall, these findings indicate that when the total number of high-frequency stimuli is held constant, a wide range of burst intervals are effective for LTP induction, with a 20 -sec burst interval being least effective and 350- to 500-msec intervals being most effective. In addition to these differences in the level of LTP produced, there were significant differences in the initial potentiation measured over the first minute following burst stimulation (ANOVA, $P<0.001$ ), with the 500-msec interval yielding significantly greater initial potentiation than the 10 -sec interval and the 1 -sec interval yielding significantly greater initial potentiation than the 5-, 10-, and 20-sec intervals (Tukey HSD, all with $P<0.05$; see Figs. 1 and $4 \mathrm{~A}$ ).

\section{Burst stimulation in AP5}

To assess the role of NMDA receptors, we examined LTP in slices treated with the competitive NMDA receptor antagonist, D-AP5 $(100 \mu \mathrm{M})$. Overall, LTP was greatly reduced by D-AP5 (Figs. 2 and
4B). LTP was consistently observed, but at a reduced level, only for continuous $100-\mathrm{Hz}$ tetanization $(15.0 \% \pm 6.0 \%, n=9)$ and for burst stimulation at a 500-msec interval $(16.2 \% \pm 4.2 \%, n=9)$. Given the reduced LTP that we observed, it is not surprising that there were no significant differences among the nine conditions that we examined (ANOVA, $P>0.20 ; n=7-11$ ). Although D-AP5 substantially reduced LTP, we found an even greater effect on the initial potentiation normally seen during the first few minutes following tetanization (cf. Figs. 1 and 2, also see Fig. 4A). In slices treated with D-AP5, an initial potentiation was seen only following continuous $100-\mathrm{Hz}$ tetanization. For burst intervals between $100 \mathrm{msec}$ and $1 \mathrm{sec}$, instead of potentiation, we observed a transient depression, and for longer burst intervals (5-20 sec) there was no effect (initial or sustained) on fEPSP slopes. The differences in initial change in fEPSP among the stimulation conditions were significant (ANOVA, $P<0.001$; significant pairwise differences between continuous tetanization and all intervals between 100 msec and $5 \mathrm{sec}$, all with $P<0.05$ ). These findings demonstrate that NMDA receptors are primarily responsible for both shortand long-term EPSP potentiation, except for continuous $100-\mathrm{Hz}$ tetanization, where NMDA receptor-independent mechanisms contribute to both short- and long-term potentiation, and the 500-msec interval, where NMDA receptor-independent mechanisms contribute to LTP.

\section{Burst stimulation in nifedipine}

To assess the role of L-type calcium channels, we reexamined the effects of continuous and burst stimulation after treatment of slices with nifedipine $(20 \mu \mathrm{M})$. In nifedipine-treated slices, sizable LTP remained at most of the intervals that were effective in standard ACSF, from 100 msec through 1 sec $(n=8-15$; see Figs. 3 and $4 \mathrm{~B})$. However, we found that the 5 -sec burst interval $(n=8)$, which was effective in the absence of any antagonists, was no longer effective when L-type calcium channels were blocked. Also, continuous $100-\mathrm{Hz}$ tetanization $(n=12)$ in the presence of nifedipine was ineffective for LTP induction. Analysis of variance revealed significant differences in LTP among the different burst intervals for nifedipine-treated slices $(P<0.001)$. Pairwise post-hoc comparisons showed significant differences (Tukey HSD, all with $P<0.05$ ) between the 500-msec burst interval and continuous $100-\mathrm{Hz}$ tetanization, and between the $500-\mathrm{msec}$ burst interval and the 5-, 10-, and 20-sec intervals. For intervals between $100 \mathrm{msec}$ and $5 \mathrm{sec}$, nifedipine had little if any effect on initial potentiation during the first minute following burst stimulation (Figs. 3 and 4A). Nifedipine did abolish initial potentiation following burst stimulation at 10 - and 20 -sec intervals and partially reduced initial potentiation following continuous $100-\mathrm{Hz}$ tetanization. Analysis of variance demonstrated significant differences in initial potentiation among the various stimulation conditions $(P<0.001)$, and post-hoc comparisons revealed significant pairwise differences between 100-, 200-, 350-, and 500msec, and 1-sec burst stimulation compared with 10- and 20-sec burst stimulation, and also significant differences between 200msec, 500-msec, and 1-sec burst stimulation compared with 5-sec burst stimulation.

Figure 4 summarizes the effects of continuous $100-\mathrm{Hz}$ tetanization and burst stimulation at intervals between $100 \mathrm{msec}$ and $20 \mathrm{sec}$ and also summarizes effects of D-AP5 and nifedipine treatment. NMDA receptors were primarily responsible for LTP induction under most of the stimulation conditions we examined, except for the continuous $100-\mathrm{Hz}$ tetanus and the 5 -sec interval, where both NMDA receptors and L-type calcium channels contributed (Fig. 4B). Although NMDA receptors were generally more important than L-type calcium channels for LTP, they were even more critical for the initial fEPSP potentiation (Fig. 4, cf. effects of D-AP5 in A and B). Although nifedipine somewhat reduced the 


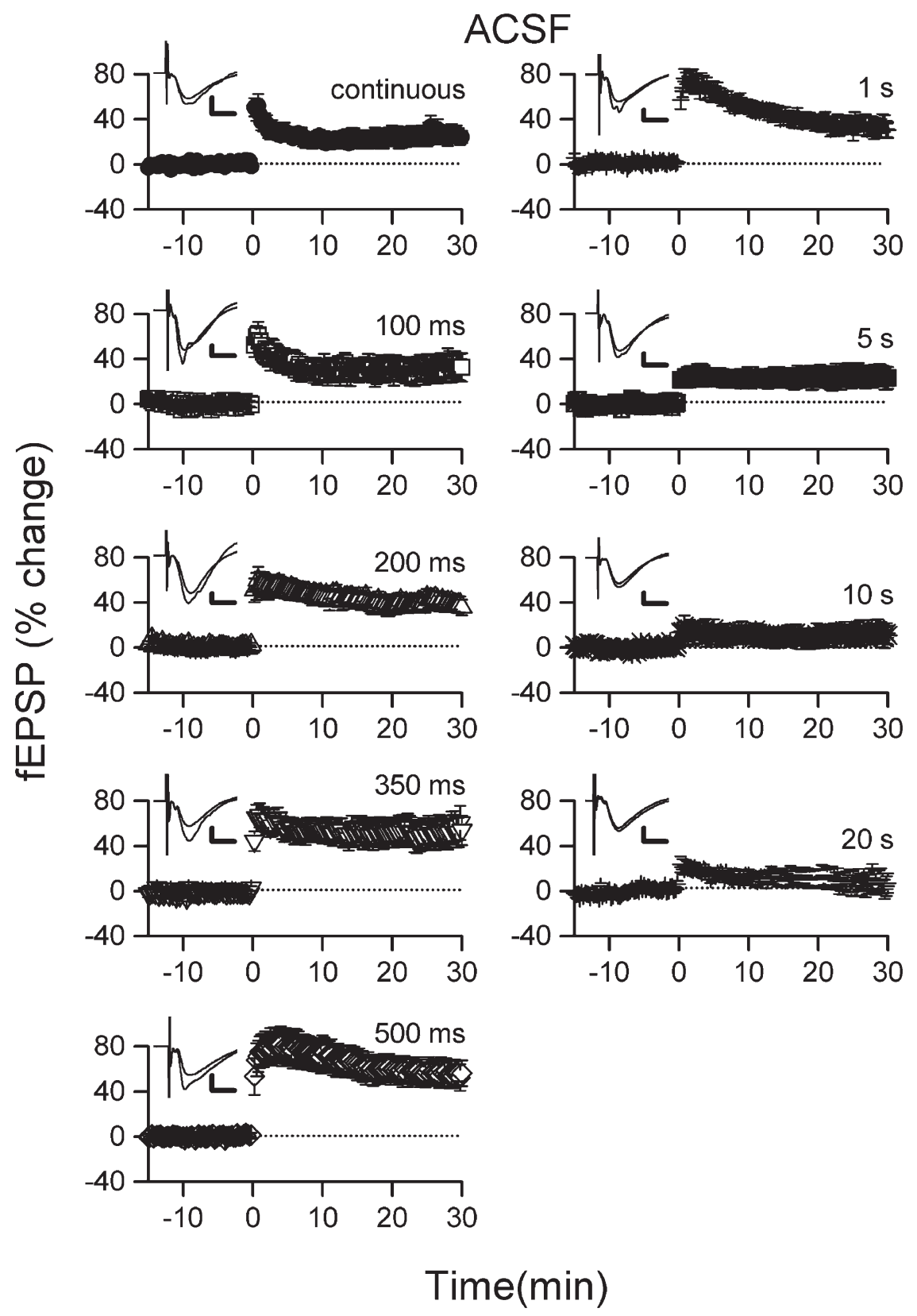

Figure 1. LTP was obtained under a wide range of stimulation conditions, including continuous 100$\mathrm{Hz}$ tetanization (top left) and burst stimulation at intervals from $100 \mathrm{msec}$ to $5 \mathrm{sec}$. Maximal LTP was obtained with burst stimulation at intervals of 350 and 500 msec. Each plot shows fEPSP change over time in response to continuous tetanization or burst stimulation at the indicated interval. Among the conditions tested, there was considerable variation in both the magnitude of LTP obtained and the post-tetanus time course of potentiation. With continuous tetanization, and also with burst stimulation at 100 -msec and 1-sec intervals, potentiation declined by about one half over the 30-min post-tetanus recording period. At burst intervals of $200-500 \mathrm{msec}$, the magnitude of LTP was greater, and there was substantially less decline from post-tetanus $\min 1$ to 30 . When burst stimulation was delivered at 5 -sec intervals, potentiation was clearly reduced, and increasing the interval between bursts to 10 or $20 \mathrm{sec}$ further decreased potentiation. However, even at the 20-sec burst interval, which failed to induce LTP, a short duration potentiation, lasting $\sim 10-20 \mathrm{~min}$, was still obtained. (Insets) Averaged fEPSPs from a representative slice recorded during the final $5 \mathrm{~min}$ of the pretetanus baseline period, and $\mathrm{min}$ 25-30 of the post-tetanus period. Calibration bars, $1 \mathrm{mV}, 5 \mathrm{msec}$.

initial level of potentiation (see Fig. 4A), in general, the effect of nifedipine was much smaller than the effect of D-AP5. Analysis of variance and subsequent post-hoc tests comparing effects of drug treatment (D-AP5, nifedipine) on initial and long-term potentia- tion revealed these significant effects (all with $P<0.05$ ): First, D-AP5 significantly inhibited LTP (compared with ACSF) at the 200-msec, 350-msec, 500-msec, and 1-sec burst intervals, but nifedipine significantly inhibited LTP at only the 350msec burst interval; second, D-AP5 significantly inhibited initial potentiation under all conditions except for the 10-sec burst interval, whereas nifedipine significantly reduced initial potentiation at only the 20-sec burst interval. Collectively, these observations demonstrate that although NMDA receptors are important for LTP induction, especially during burst stimulation, they are even more important for the initial potentiation, regardless of whether this initial potentiation is triggered by a continuous tetanus or a series of short bursts.

\section{Dimethyl sulfoxide (DMSO) control}

Nifedipine was dissolved in dimethyl sulfoxide (DMSO) prior to dilution into the perfusate. To ensure that putative drug effects reflected the action of nifedipine and not the DMSO vehicle, we tested effects of DMSO alone on LTP obtained by continuous $100-\mathrm{Hz}$ tetanization and burst stimulation at the 500msec interval. DMSO by itself $(n=6)$ had no effects on LTP (for continuous $100-\mathrm{Hz}$ tetanization, $24.7 \% \pm 7.0 \%$ in ACSF vs. $24.7 \% \pm 6.1 \%$ in DMSO, $P>0.20$; for 500-msec burst interval, $52.2 \% \pm 10.8 \%$ in ACSF vs. $43.2 \% \pm 5.5 \%$ in DMSO, $P>$ $0.50)$. Likewise, DMSO had no effect on the initial potentiation of fEPSPs (for continuous $100-\mathrm{Hz}$ tetanization, $49.0 \% \pm$ $9.2 \%$ in ACSF vs. $57.9 \% \pm 13.0 \%$ in DMSO, $P>0.20$; for 500-msec burst interval, $65.9 \% \pm 12.6 \%$ in ACSF vs. $72.2 \% \pm$ $16.7 \%$ in DMSO, $P>0.69$ ).

We also tested the combination of both D-AP5 and nifedipine on LTP following burst stimulation at the $500-\mathrm{msec}$ interval $(n=7)$. The combination of calcium entry blockers completely prevented both long-term and initial potentiation (mean change in fEPSP slope of $2.7 \% \pm 6.4 \%$ at $25-30 \mathrm{~min}$ post and $-3.5 \% \pm 4.9 \%$ at $0-1$ min post). The lack of any immediate or long-lasting consequences when both NMDA receptors and L-type calcium channels were blocked indicates that, at least under our experimental conditions, no additional calcium entry pathways are required.

\section{Primed burst stimulation}

Our data indicate maximal LTP with burst stimulation at intervals of 350 and $500 \mathrm{msec}$. This result was unexpected, given the previous reports that theta frequency (200-msec interval) is optimal for LTP induction. In these previous studies, however, the most detailed information available is from the primed burst protocol, and it has 


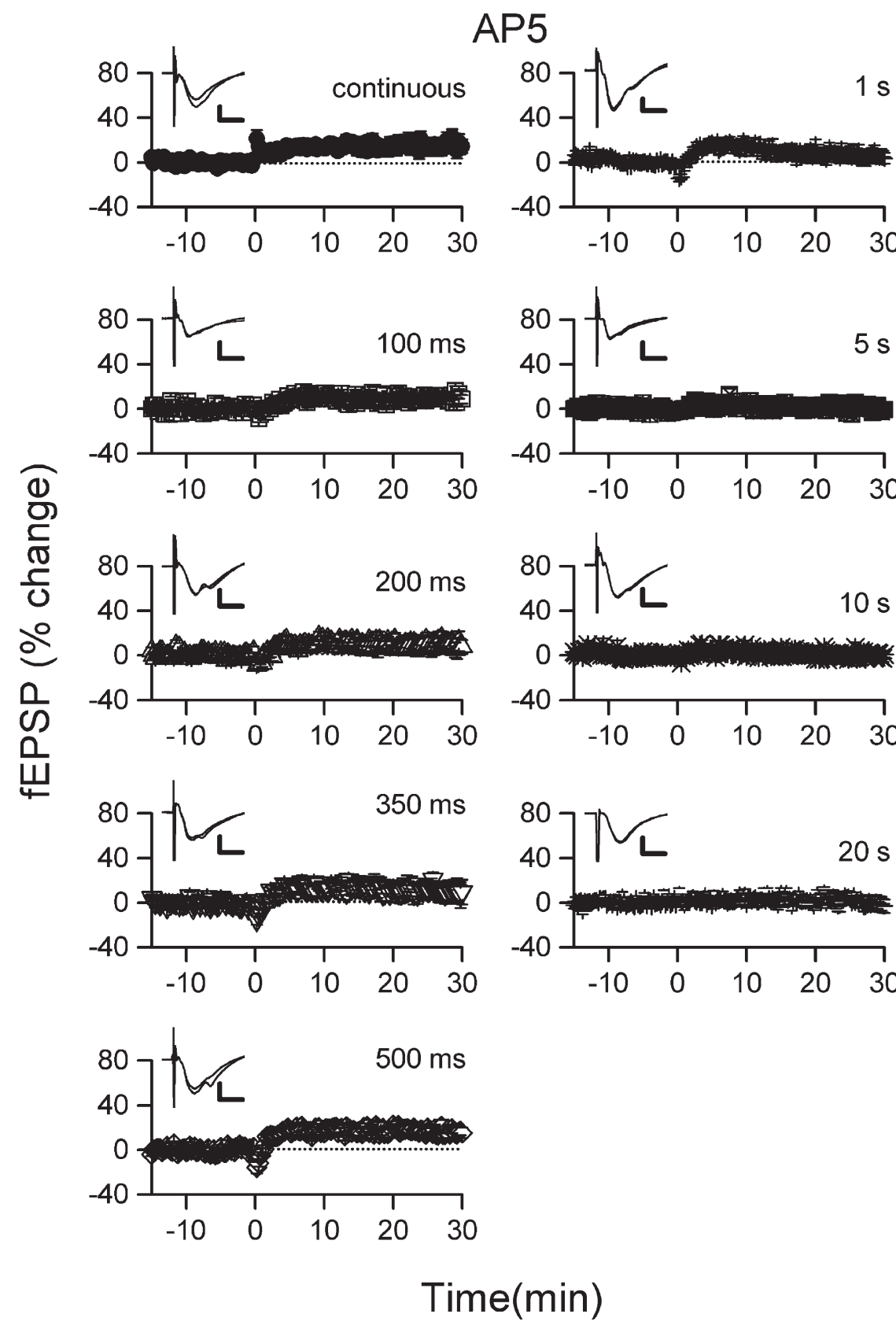

Figure 2. The NMDA receptor antagonist D-AP5 $(100 \mu \mathrm{M})$ greatly reduced potentiation. As in Figure 1 , each plot shows fEPSP change over time in response to continuous tetanization (top left) or burst stimulation at the indicated interval. LTP induced by continuous $100-\mathrm{Hz}$ tetanization in D-AP5 most closely resembled the NMDA receptor-independent LTP previously reported (Grover and Teyler 1990, 1994; Cavus and Teyler 1996), with an initial post-tetanic increase in fEPSP slope that decayed almost back to baseline over the first few minutes post-tetanus and was followed by a gradual increase in EPSP slope over the next 10 min before reaching a stable level of potentiation. Burst stimulation at 100- to 350-msec intervals was largely ineffective for LTP induction, but a small level of potentiation was obtained by burst stimulation at the 500-msec interval. Burst intervals of $1 \mathrm{sec}$ or longer resulted in little or no LTP. In contrast to results obtained in standard ACSF (no NMDA receptor antagonist, Fig. 1), for all burst intervals between $100 \mathrm{msec}$ and $1 \mathrm{sec}$, EPSP depression rather than potentiation was present over the first few minutes post-tetanus. (Insets) Averaged fEPSPs from a representative slice recorded during the final 5 min of the pretetanus baseline period and min 25-30 of the post-tetanus period. Calibration bars, $1 \mathrm{mV}, 5 \mathrm{msec}$.

generally been assumed that the optimal interval for primed burst and repeated burst stimulation would be identical. To test this assumption, we compared results with the 200- and 500-msec intervals using the primed burst and multiple repeated burst protocols. We chose these two intervals because they include the optimal interval based on previous studies using the primed burst protocol $(200 \mathrm{msec})$ and the interval that we found produced the best LTP following repeated multiple bursts (500 msec).

In agreement with previous studies of primed burst potentiation, we found that a 200 -msec interval between priming stimulation and a single burst of four stimuli was effective (fEPSP increase of $16.6 \% \pm 3.9 \%, n=6$ ), but a $500-\mathrm{msec}$ interval failed to induce LTP (fEPSP change of $2.1 \% \pm 3.2 \%$; see Fig. $5, n=$ 6). The difference between the two priming intervals was significant $(P<0.02)$. In contrast, when multiple repeated bursts were used to induce LTP, the magnitude of potentiation was greater for the 500msec interval $(52.2 \% \pm 10.8 \%, n=12)$ than for the $200-\mathrm{msec}$ interval $(40.5 \% \pm$ $6.8 \%, n=12$; see Figs. $1,4 \mathrm{~B}$, and $5 \mathrm{C}$ ), although this difference was not significant. These differences between primed burst and multiple repeated bursts suggest that different mechanisms are engaged to generate the postsynaptic depolarization required for LTP induction depending on the pattern of stimulation (primed burst or multiple repeated bursts). To determine what factors may be essential for LTP induction by repeated burst stimulation, we examined the postsynaptic responses of CA1 pyramidal neurons during burst stimulation using whole-cell current clamp recordings.

\section{Postsynaptic responses to burst stimulation}

We recorded postsynaptic membrane potential during continuous $100-\mathrm{Hz}$ tetanization and burst stimulation at 200-msec, 500-msec, and 1-sec intervals. We chose these intervals because they include the most effective interval in our LTP studies (500 $\mathrm{msec})$, the interval previously suggested as optimal for LTP induction (200 $\mathrm{msec})$, and two additional intervals that yielded reduced LTP (continuous tetanization and burst stimulation at $1-\mathrm{sec}$ intervals). Stimulation intensities were adjusted to spike threshold level so that burst stimulation conditions would be comparable with our previous field potential recordings. Representative recordings from four different cells, each of which received burst stimulation at one of the four intervals, are shown in Figure 6. Depending on the burst interval used, the postsynaptic response to burst stimulation differed considerably. When stimulation was delivered as a continuous $100-\mathrm{Hz}, 800-\mathrm{msec}$ tetanus, individual EPSPs readily summed across the entire period of stimulation because the interval between stimuli (10 msec) was shorter than the duration of individual EPSPs (Fig. 6A). Action 

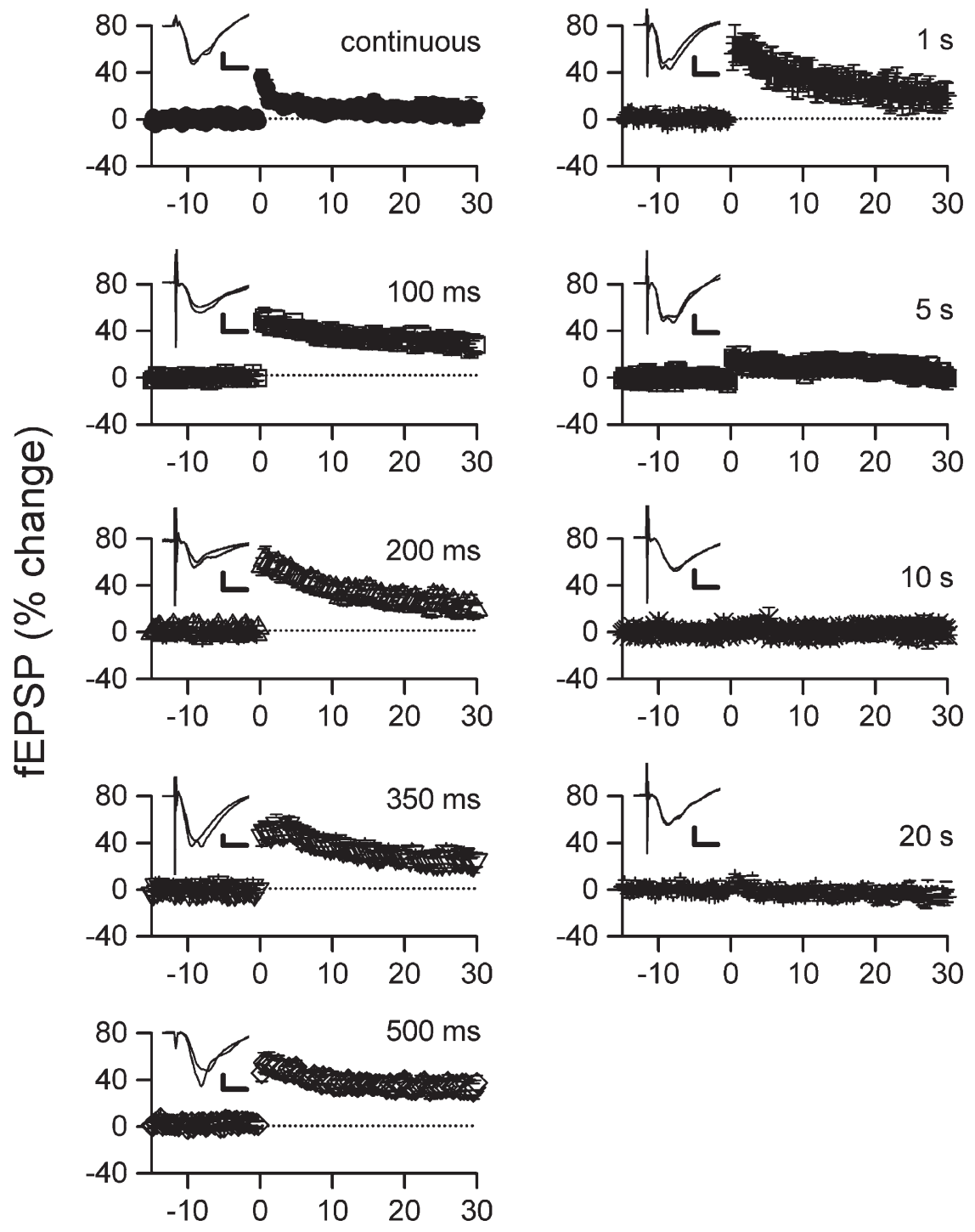

\section{Time $(\min )$}

Figure 3. The L-type calcium channel antagonist nifedipine $(20 \mu \mathrm{M})$ strongly inhibited LTP following continuous $100-\mathrm{Hz}$ tetanization but had a relatively small effect on LTP induced by burst stimulation. As in Figures 1 and 2, each plot shows fEPSP change over time in response to the indicated stimulation condition (continuous tetanization or burst stimulation). Nifedipine had little or no effect on the initial potentiation observed following burst stimulation for intervals between $100 \mathrm{msec}$ and $5 \mathrm{sec}$ but did accelerate the rate of decay of potentiation over the 30-min period (compare LTP time courses with time courses shown Fig. 1). (Insets) Averaged fEPSPs from a representative slice recorded during the final $5 \mathrm{~min}$ of the pretetanus baseline period and $\min 25-30$ of the post-tetanus period. Calibration bars, $1 \mathrm{mV}, 5 \mathrm{msec}$.

potential firing was initially brisk but was confined to the first 200 msec of stimulation. The decline in firing appeared to be a consequence of EPSP depression, which was observed within the first 100 msec of stimulation.

When stimuli were delivered as discrete bursts separated by $200 \mathrm{msec}, 500 \mathrm{msec}$, or $1 \mathrm{sec}$, action potential firing increased with burst number (Fig. 6B-D). This increase in firing was most likely due, at least in part, to a cumulative loss of synaptic inhibition across repeated bursts. The loss of inhibition occurred most rapidly for the 200-msec burst interval (Fig. 6B), where the post-burst hyperpolarization - caused by synaptic activation of both $\mathrm{GABA}_{\mathrm{A}}$ and $\mathrm{GABA}_{\mathrm{B}}$ receptors-was largely or completely suppressed during the second and all following bursts. A similar, though slower, decline in synaptic inhibition was seen during burst stimulation at the 500 -msec interval, where 7-8 bursts (Fig. 6C) were required before post-burst inhibition was lost. When bursts were separated by $1 \mathrm{sec}$, the decline in inhibition was even slower, and in many cells, including the cell shown in Figure 6D, was incomplete even after 20 bursts.

To quantify and compare changes among cells receiving burst stimulation at different intervals, we made the following measurements (see Fig. 6E): membrane potential immediately before delivery of each burst, slope of the first EPSP in each burst, number of action potentials fired in each burst, and the amplitude of the inhibitory postsynaptic potential (IPSP) that followed each burst (for burst intervals of $200 \mathrm{msec}-1$ sec only). We examined 6-7 cells for each of the four conditions. As shown in Figure 7A, action potential firing during continuous $100-\mathrm{Hz}$ stimulation rapidly declined and was virtually absent after the 16th stimulus (corresponding to the fourth burst). In contrast, cells that received burst stimulation at 200 msec-1 sec typically increased firing across repeated bursts, with the greatest level of firing observed during the final 10 bursts at the $500-\mathrm{msec}$ interval. To compare across conditions, we summed action potentials across all 20 bursts and found significant differences among the four intervals (ANOVA, $P<0.001)$. Post-hoc comparisons revealed significantly greater $(P<0.05)$ firing for $200-\mathrm{msec}$, $500-\mathrm{msec}$, and 1 -sec intervals compared with continuous tetanization. No other pairwise comparisons were significant.

The differences in firing among the four conditions might reflect different degrees of EPSP summation. Comparison of the membrane potential recorded immediately before delivery of each burst, however, indicated that this was not the case. Because of the absence of time between bursts, EPSPs summed most effectively during continuous stimulation (Fig. 7B), with a maximal depolarization of $14.4 \pm 1.6 \mathrm{mV}$, yet overall firing was lowest for this stimulation condition (Fig. 7, cf. B with A). Cells receiving burst stimulation at $200-\mathrm{msec}$ intervals showed the next greatest degree of summation, depolarizing by $8.3 \pm 1.8 \mathrm{mV}$ (Fig. 7B). The 200-msec interval between bursts is too long for summation of fast, $\alpha$-amino-3-hydroxy-5-methyl4-isoxazolepropionic acid (AMPA) receptor-mediated EPSPs, and instead, this depolarization most likely reflects summation of slower NMDA receptor-mediated EPSPs, which become increasingly prominent across bursts due to loss of synaptic inhibition. Cells receiving bursts at the 500-msec interval showed reduced 

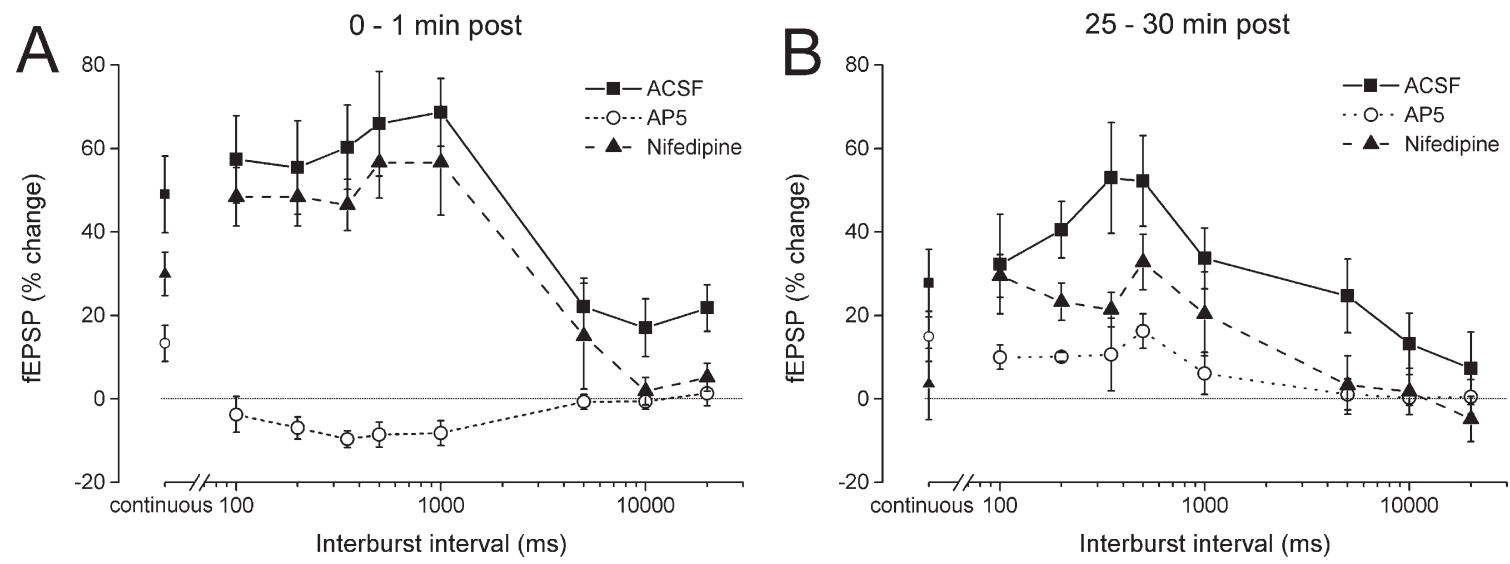

Figure 4. Initial (0-1 post) and long-term (25-30 min post) potentiation were induced over a wide range of stimulation conditions. Each point plots the mean change in fEPSP measured over the indicated post-tetanus time period for continuous tetanization or burst stimulation at intervals between 100 msec and $20 \mathrm{sec}$. Data (from same slices as shown in Figs. 1-3) are shown for recordings in standard ACSF, $100 \mu \mathrm{M}$ D-AP5, and $20 \mu \mathrm{M}$ nifedipine. (A) Initial potentiation was observed under all stimulation conditions in standard ACSF and with burst intervals up to 5 sec with L-type calcium channels blocked. In standard ACSF, continuous tetanization and burst stimulation at intervals from $100 \mathrm{msec}$ to 1 sec caused equivalent fEPSP potentiation. Burst stimulation at intervals from 5 to $20 \mathrm{sec}$ was less effective, but even at these longer intervals fEPSPs were still initially increased by about $20 \%$ in standard ACSF. Potentiation during the first minute was completely blocked by D-AP5, except for continuous tetanization, where D-AP5 reduced but did not eliminate potentiation. With NMDA receptors blocked by D-AP5, burst stimulation at intervals from $100 \mathrm{msec}$ to 1 sec resulted in an initial depression instead of the potentiation that was seen in normal ACSF. Nifedipine had little effect over intervals from 100 msec to 5 sec but did decrease the potentiation that normally followed continuous tetanization and burst stimulation at 10- and 20-sec intervals. (B) When LTP was examined in standard ACSF, a wide range of conditions was effective, from continuous tetanization to burst stimulation at 5-sec intervals, but LTP was maximal with bursts given at 350- to 500-msec intervals. When NMDA receptors were blocked by AP5, LTP was reduced over the entire range of intervals, but some residual LTP was obtained with continuous tetanization and with burst stimulation at intervals up to $1 \mathrm{sec}$. The L-type calcium channel blocker nifedipine blocked LTP induction by continuous tetanization, and by burst stimulation at the 5 -sec interval, but caused only a partial inhibition of LTP at burst intervals between $200 \mathrm{msec}$ and $1 \mathrm{sec}$.

summation $(3.2 \pm 0.9 \mathrm{mV})$, and cells receiving bursts at the 1 -sec interval showed essentially no summation across bursts $(-0.7$ $\pm 0.8 \mathrm{mV}$ ). The reduced or absent summation during burst stimulation at $500-\mathrm{msec}$ or 1 -sec intervals presumably reflects the greater duration of the burst interval compared with the duration of the NMDA receptor-mediated EPSPs. Although there were large and significant differences in EPSP summation across the four conditions (ANOVA, $P<0.001$ ), these differences cannot explain the differences in action potential firing. The most effective summation occurred under the same stimulation condition that yielded the lowest overall firing, continuous $100-\mathrm{Hz}$ tetanization. In addition, the $200-\mathrm{msec}$ burst interval produced significantly greater summation $(P<0.02)$ than the 1 -sec burst interval, yet firing was not greater. Rather than reflecting differences in EPSP summation, the differences in firing rate must be caused by other differences among the four conditions, such as changes in excitatory or inhibitory synaptic transmission.

Measurement of the slope of the first EPSP in each burst indicates that at least some of the differences in firing can be explained by differing effects of stimulation on EPSPs (see Fig. 7C). During continuous tetanization EPSPs showed substantial depression, declining to $62.6 \% \pm 7.6 \%$ of the initial slope. EPSPs during 200 -msec and 1-sec burst stimulation changed little across repeated bursts. At burst 20, EPSPs averaged $96.9 \% \pm 5.2 \%$ and $92.5 \% \pm 7.4 \%$ of initial slope. Cells receiving burst stimulation at 500-msec intervals, in contrast, showed EPSP facilitation across bursts (mean of $131.1 \% \pm 16.1 \%$ at burst 20). These differences were significant (ANOVA, $P<0.002$ ). Pairwise comparisons showed that the EPSP change at the end of burst stimulation at the 500-msec interval was significantly different from that of cells receiving continuous tetanization $(P<0.001)$ or burst stimulation at the 1 -sec interval $(P<0.05)$ intervals.

We also examined changes in synaptic inhibition across repeated bursts. Differences in inhibition among the four conditions can also explain at least a portion of the differences in firing levels. To quantify inhibition, for each cell we first determined the latency to the peak of the hyperpolarization following the first burst and then measured the change in membrane potential at this latency across all 20 bursts. While this measurement reflects the strength of synaptic inhibition, it is also influenced by the presence of slow NMDA receptor-mediated excitation. Consequently, this measurement indicates relative changes in inhibition compared with NMDA receptor-mediated excitation. As expected from previous studies showing decreased inhibition when stimulation was repeated at theta frequency, we found strong suppression of inhibition during burst stimulation at $200 \mathrm{msec}$ (Fig. 7D). In most cells, post-burst hyperpolarization was present after only the first burst and was replaced with depolarization from bursts 2-20. Burst stimulation at 500-msec intervals was somewhat less effective in suppressing inhibition, and burst stimulation at 1-sec intervals was much less effective in suppressing inhibition, although even with the 1-sec interval, post-burst hyperpolarization was still lost by burst 8 . All three burst intervals, $200 \mathrm{msec}, 500 \mathrm{msec}$, and $1 \mathrm{sec}$, led to systematic declines in inhibition across repeated bursts. These changes in synaptic inhibition in combination with the changes in excitation noted above can explain the different patterns of action potential firing we observed (Fig. 7A).

\section{Effects of calcium entry blockers on postsynaptic response to burst stimulation}

In a final set of recordings, we examined effects of D-AP5 and nifedipine on the postsynaptic response during burst stimulation. We examined two stimulation conditions, continuous tetanization and repeated burst stimulation at 500-msec intervals. We chose these intervals because (1) the postsynaptic response during continuous tetanization was different than the responses to burst stimulation at any interval examined, (2) there were smaller differences in postsynaptic response among the 200-msec, 
A

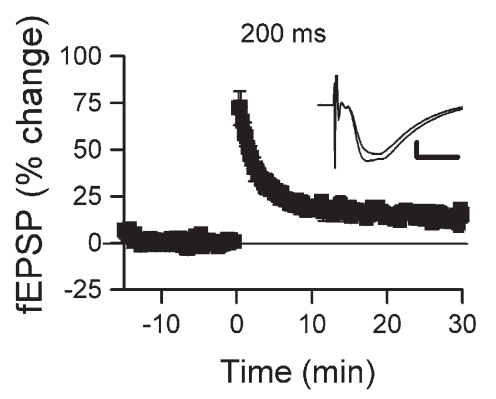

C

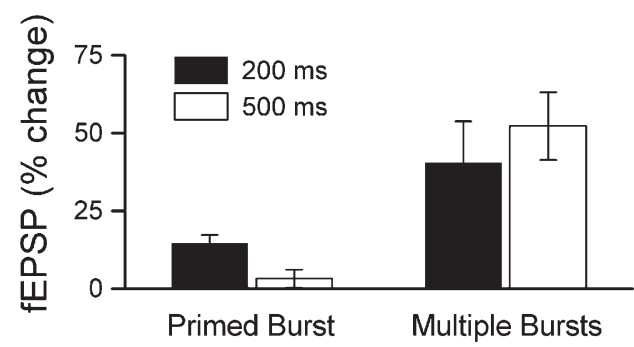

Figure 5. LTP resulting from a single primed burst was significantly greater when an interval of 200 msec was used compared with an interval of 500 msec. In contrast, $200 \mathrm{msec}$ was not superior when repeated bursts of stimulation were used. (A) A single burst of stimulation given 200 msec after a priming stimulus resulting in a large initial increase in fEPSP slope that decayed over 15-20 min into a small but stable LTP. (B) When the interval between the priming stimulus and the burst was increased to $500 \mathrm{msec}$, an initial increase in fEPSP slope was still obtained; however, the potentiation completely decayed over a 15-min period, and no LTP was present. (C) LTP magnitude obtained with primed burst stimulation compared with LTP obtained by repeated bursts of stimulation. Intervals between the priming stimulus and the burst, or between successive bursts, were 200 and $500 \mathrm{msec}$. For primed burst stimulation, LTP was present only when an interval of $200 \mathrm{msec}$ was used, and the change in fEPSP was significantly greater than when the priming interval was $500 \mathrm{msec}(P<0.02)$. When multiple bursts of stimulation were given, at either 200- or 500-msec intervals (same data as shown in Figs. 2 and 5), greater LTP was obtained with the 500-msec interval, but the difference was not significant.

500-msec, and 1-sec burst intervals than there were between any of the burst stimulation conditions and continuous tetanization, and (3) burst stimulation at the 500-msec interval was most effective for LTP induction. Figure 8 summarizes results from this final set of recordings and for comparison also includes data from Figure 7 for cells receiving the same stimulation in standard ACSF.

Neither D-AP5 nor nifedipine consistently altered the postsynaptic response during continuous $100-\mathrm{Hz}$ tetanization. D-AP5, but not nifedipine, reduced action potential firing across repeated bursts at the 500-msec interval reflecting the inhibition of NMDA receptor-dependent postsynaptic depolarization (Fig. 8A). Neither D-AP5 nor nifedipine altered summation during either burst stimulation or continuous tetanization (Fig. 8B). Similarly, neither D-AP5 nor nifedipine altered EPSP facilitation during burst stimulation at 500-msec intervals or EPSP depression during continuous $100-\mathrm{Hz}$ tetanization (Fig. 8C). While D-AP5, but not nifedipine, appeared to reduce the suppression of synaptic inhibition across repeated bursts at the 500-msec interval (Fig. 8D), this effect most likely reflects a block of NMDA receptor-dependent postsynaptic depolarization and not a true sparing of GABA receptor-dependent inhibition. It was somewhat surprising that the block of NMDA receptors by D-AP5 had relatively little effect on the postsynaptic response to continuous tetanization given previous findings (Herron et al. 1986; Collingridge et al. 1988), but this observation is consistent with our LTP data that showed a relatively weak effect of D-AP5 on potentiation by continuous 100-Hz tetanization. terval, but not at the longer interval. The contrast between our single primed burst and our repeated burst data indicates a difference in underlying synaptic mechanisms.

Considerable evidence supports a critical role for $G_{A B A}$ autoreceptor-mediated suppression of inhibition during LTP induction by primed burst stimulation. $\mathrm{GABA}_{\mathrm{B}}$ autoreceptors maximally suppress GABA release when priming stimulation precedes a stimulus burst by 150-200 msec (Davies et al. 1990; Davies and Collingridge 1993; Mott et al. 1993), and suppression of inhibition during the primed burst is critical for activation of NMDA receptors (Morrisett et al. 1991; Davies and Collingridge 1996) and LTP induction (Larson and Lynch 1986; Pacelli et al. 1989). Because $\mathrm{GABA}_{\mathrm{B}}$ autoreceptor-mediated inhibition of GABA release is less effective when stimulation intervals exceed $200 \mathrm{msec}$, and because we observed strong suppression of inhibition even at 1-sec intervals between bursts, we suggest that an additional process must underlie the progressive loss of inhibition during repeated burst stimulation at intervals $\geq 500 \mathrm{msec}$. Several potential mechanisms exist. Decreased inhibition might be postsynaptic in origin, involving, for example, receptor desensitization or altered ion concentration gradients (Thompson and Gähwiler 1989a,b,c). Decreased inhibition could also be presynaptic in origin, due to depletion of GABA vesicles or altered coupling between presynaptic action potentials and vesicle release (Jensen et al. 1999; Kraushaar and Jonas 2000). Retrograde signaling from postsynaptic neurons to presynaptic GABA terminals (Alger et al. 1996; Reich et al. 2005) could also suppress inhibition during burst stimulation. Finally, some combination of mechanisms may be required 
A
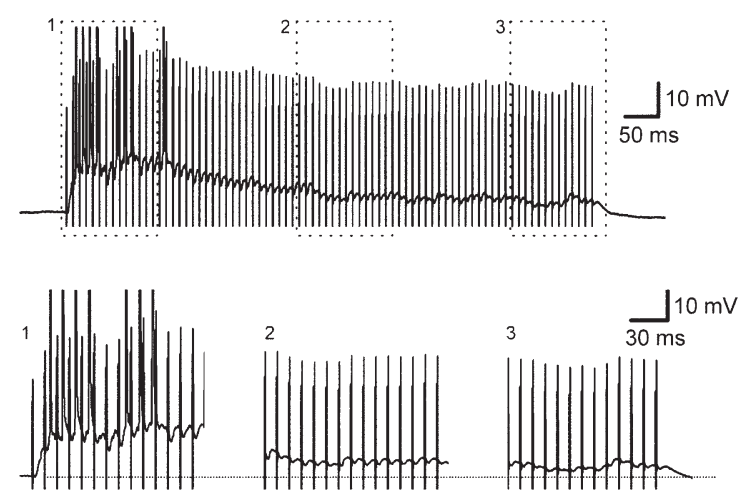

C
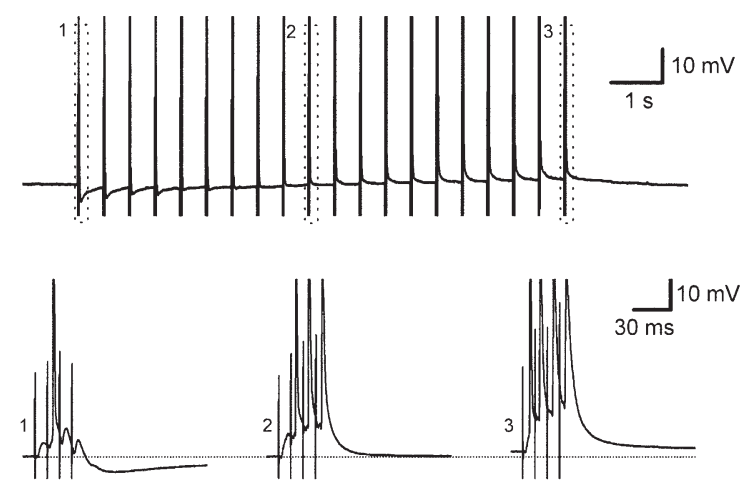

E

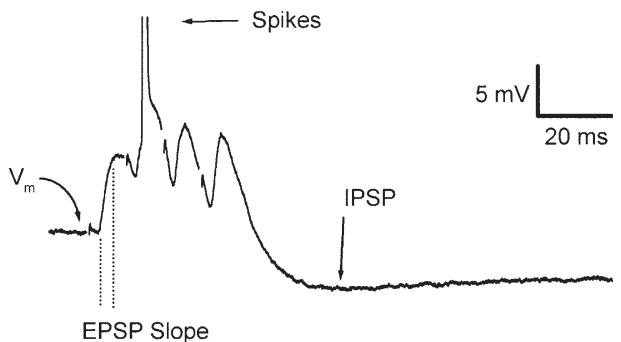

B
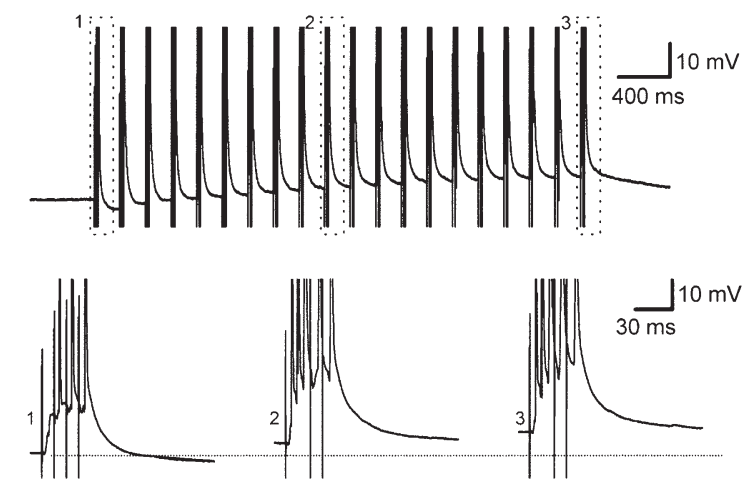

D
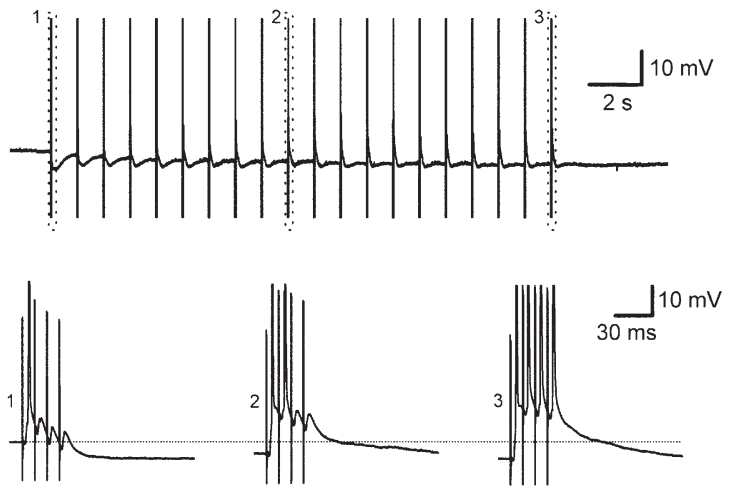

Figure 6. Continuous tetanization and burst stimulation at 200-msec, 500-msec, and 1-sec intervals caused different responses in postsynaptic shown. For each recording, the top shows responses to all 80 stimuli (note the differences in horizontal timescale), and the bottom shows responses from the beginning, middle, and end of stimulation (fine dotted line indicates baseline resting membrane potential). (A) Continuous $100-\mathrm{Hz}$ tetanization caused a large depolarization due to EPSP summation. Depolarization was initially sufficient to trigger action potential firing, but as stimulation continued, individual EPSPs declined in amplitude, the membrane potential returned back toward the resting level, and firing stopped. Although EPSPs were substantially reduced after a few hundred milliseconds, the membrane potential remained depolarized through the end of HFS. (B) Action potential firing increased across bursts given at 200-msec intervals. Firing increased because of rapid loss of post-burst inhibition and maintained EPSP amplitude, in contrast to the EPSP depression that occurred during continuous $100-\mathrm{Hz}$ stimulation. The loss of post-burst inhibition allowed membrane potential to gradually depolarize across repeated bursts, due to summation of slower NMDA receptor-mediated EPSPs. (C) As with burst stimulation at a 200-msec interval, action potential firing increased across repeated bursts given at 500-msec intervals. Although the decline in post-burst inhibition was slower with 500 -msec burst stimulation, inhibition was still strongly suppressed after several bursts. Membrane potential showed less cumulative depolarization in comparison with the 200-msec interval, due to the slower decline in inhibition, and the longer, 500-msec interval between bursts, which did not favor summation of NMDA receptor-mediated EPSPs. (D) Burst stimulation at 1 -sec intervals, as with 200- and 500-msec intervals, caused increased firing across bursts, gradual (though incomplete) decrease in post-burst inhibition, and sustained EPSP amplitudes. In contrast to the 200- and 500-msec intervals, when bursts were given at 1-sec intervals, there was no cumulative depolarization of the postsynaptic membrane, and some cells, like the cell shown here, showed a cumulative hyperpolarization. ( $E$ ) Measurements used to quantify the effects of continuous and burst stimulation on postsynaptic neurons. Shown here in greater detail is the response of the cell in $C$ to the first of 20 bursts of stimulation (stimulus artifacts removed for clarity). Four measurements were made: (1) number of action potentials (Spikes) fired during each burst, (2) membrane potential $\left(V_{m}\right)$ immediately prior to each burst, (3) the slope of the first EPSP in each burst (EPSP Slope), and (4) the change in membrane potential (compared to $V_{m}$ ) at a time point corresponding to the peak hyperpolarization following the first burst (IPSP).

for the strong suppression of inhibition, which we observed during burst stimulation.

Another factor that may contribute to LTP induction by burst stimulation at the 500-msec interval is a progressive facilitation of excitatory synaptic transmission. We observed EPSP facilitation only during burst stimulation at the 500-msec interval, and not at shorter $(200 \mathrm{msec})$ or longer $(1 \mathrm{sec})$ intervals. Most likely, facilitation of EPSPs and suppression of IPSPs both contribute to the effectiveness of the 500-msec burst interval. Reduced LTP following burst stimulation at 200-msec and 1-sec intervals can be 
explained by a lack of EPSP facilitation, which was not observed at the 200-msec or 1-sec intervals, and by less effective suppression of IPSPs at the 1 -sec interval.

While there were differences among the 200-msec, 500-msec, and 1-sec intervals in postsynaptic response to burst stimulation, these differences were much smaller than the differences between continuous tetanization and any of the three burst stimulation patterns. The most prominent of these differences was in the total number and pattern of action potentials fired. When all 80 stimuli were presented as a single $100-\mathrm{Hz}$ train, action potential firing declined rapidly and was virtually absent during the final three quarters of the stimulation period. When synaptic stimulation was given as a series of bursts, however, firing progressively increased. This profound difference in part reflects the EPSP depression that occurs during continuous tetanization but does not occur when stimuli are grouped into discrete bursts. The strong depression of EPSPs during continuous stimulation may also explain the reduced role of NMDA receptors in LTP induced by continuous stimulation compared with LTP induced by burst stimulation. If this EPSP depression reflects presynaptic release failure, then there will be decreased glutamate available for NMDA receptor activation. In contrast to continuous HFS, NMDA receptors appear to remain activated across multiple bursts of stimuli, as revealed by the effects of the NMDA receptor blocker D-AP5 during burst stimulation at the 500-msec interval.

In general, except for continuous HFS, NMDA receptors were more important for both initial potentiation and LTP than were L-type calcium channels. For all burst intervals between $100 \mathrm{msec}$ and $5 \mathrm{sec}, \mathrm{D}-\mathrm{AP} 5$ greatly decreased potentiation over the entire post-tetanus recording period. In comparison, nifedipine had generally weaker effects, except for continuous tetanization, where nifedipine was a more effective inhibitor of LTP than was D-AP5, and for burst stimulation at intervals $\geq 5 \mathrm{sec}$, where nifedipine and D-AP5 were equally effective inhibitors of LTP. The reduced role of NMDA receptors compared with L-type calcium channels during continuous tetanization may be a consequence of the strong EPSP depression that occurs with continuous HFS, and which, as discussed above, may limit NMDA receptor activation. The equivalent effectiveness of nifedipine and D-AP5 as LTP inhibitors at burst intervals $\geq 5$ sec could be a consequence of the longer period over which postsynaptic calcium signals can decay. At shorter burst intervals, postsynaptic calcium signals may be able to sum across individual bursts to reach the level required for LTP induction, and calcium entry by a single transmembrane route may be sufficient. At longer burst intervals, when summation of postsynaptic calcium signals is reduced, both routes for calcium entry may be required to achieve a level sufficient for LTP induction.
Summation of postsynaptic calcium signals under the different stimulation protocols can be explored with computational models. Previously, we modeled calcium influx through NMDA receptor channels and subsequent calcium/calmodulindependent protein kinase II (CaMKII) activation in dendritic spines (Holmes 2000). This model predicted that the level of CaMKII activation depended on the repetition interval of a short tetanus, but the optimal interval was much longer than found here because of NMDA receptor desensitization. This difference in optimal interval suggests that NMDA receptor desensitization was not as prominent in our experiments, perhaps because synaptic failure (Hessler et al. 1993; Stevens and Wang 1995) during LTP induction limited the desensitization of NMDA receptors (synaptic failure was not a feature of the previous model).

In summary, there are several factors that could determine the optimal interval for LTP induction by burst stimulation. The level of postsynaptic depolarization during burst stimulation is
A

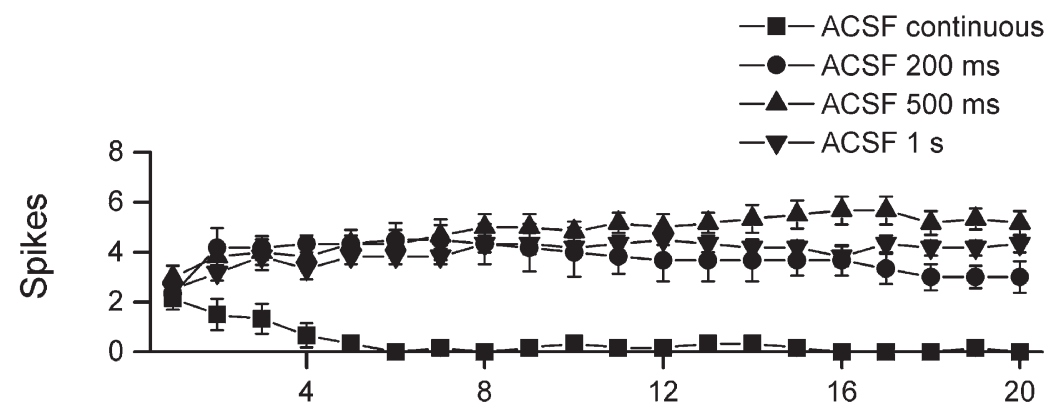

B

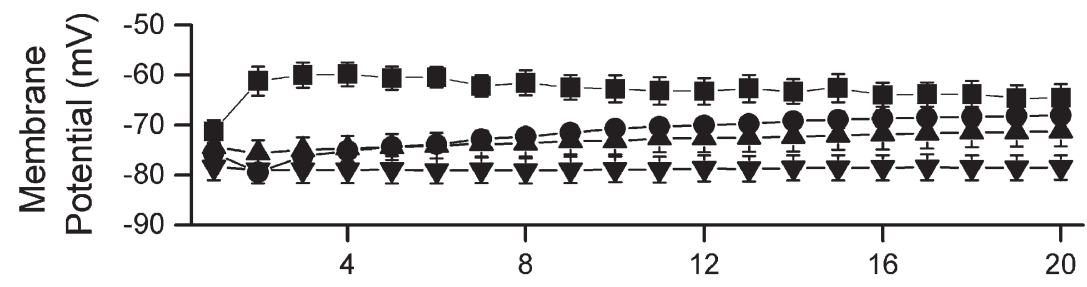

C

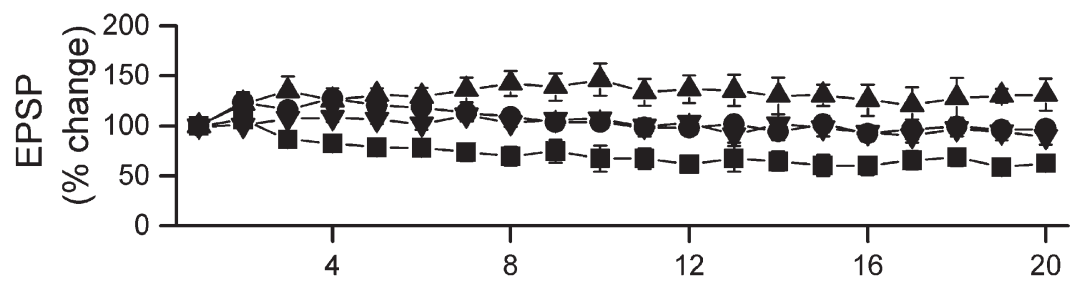

D

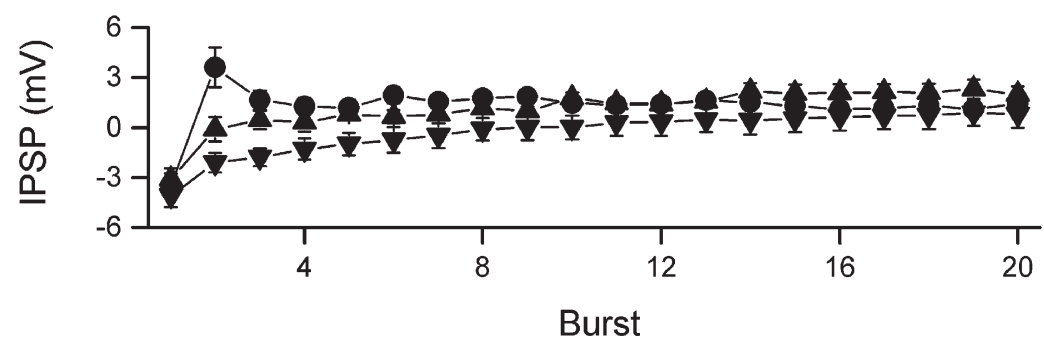

Figure 7. (Legend on next page) 
certainly a key factor because the postsynaptic calcium influx that triggers LTP is voltage dependent. We identified two processes that regulate postsynaptic depolarization during burst stimulation, suppression of inhibition and facilitation of excitation, but at present we cannot say quantitatively how these processes combine to alter calcium influx through NMDA receptors or L-type calcium channels. A complicating factor is the degree to which receptor desensitization, or channel inactivation, may alter calcium influx with different intervals of burst stimulation. A second critical factor is the effectiveness of postsynaptic calcium signals in engaging downstream pathways. Depending on the burst interval used, the timing of these signals will differ, and this will affect activation of CaMKII and other calcium-regulated molecules. Finally, there may be interactions among the two calcium influx routes, NMDA receptors and L-type calcium channels. Interactions could occur through effects on membrane potential, summation of calcium signals, or calcium-dependent modulation of channel activity. Assessing the relative importance of these factors in the optimal burst interval for LTP induction will require further experimentation.

Repetitive, synchronized synaptic input to area CA1 occurs under physiological conditions in the behaving animal. Theta frequency oscillations, in particular, have attracted considerable attention, and it has been known for several years that Schaffer collateral/commissural synapses are efficiently potentiated by repeated bursts of stimulation delivered at 200-msec intervals (5$\mathrm{Hz}$ theta frequency). While our results support theta frequency burst stimulation as an effective stimulus for LTP induction, we found that burst stimulation at slightly lower frequencies $(2-3 \mathrm{~Hz}$, or delta frequency) was even more effective. Although theta frequency activity is prominent in the hippocampus under some behavioral conditions, slower EEG frequencies dominate under other conditions, including slow wave sleep (Buzsáki 1986; Suzuki and Smith 1987; Wolansky et al. 2006; Moroni et al. 2007). Our results suggest that synchronized bursts of presynaptic activity, even at relatively low frequencies, could be quite effective for LTP induction. In addition, short-term plasticity, lasting up to $\sim 10$ min, occurred over the entire range of burst intervals that we examined, including the 10- and 20-sec intervals, which did not reliably induce LTP. The ability of excitatory synapses onto CA1 pyramidal cells to potentiate, for short to long durations, in response to brief bursts of presynaptic activity over such a wide range of frequencies $(0.05-10 \mathrm{~Hz})$ suggests that virtually all of the previously reported physiological patterns of population synchronization in the hippocampus, from low-frequency oscillations ( $\leq 1 \mathrm{~Hz}$ ) (Wolansky et al. 2006; Moroni et al. 2007) through theta rhythms (up to $12 \mathrm{~Hz}$ ) (Vanderwolf 1969; Whishaw and Vanderwolf 1973) are capable of triggering short- to long-term synaptic enhancement of excitatory synaptic transmission. The broad frequency tuning of CA1 synapses for synaptic enhancement, which was not shown previously, allows area CA1 to contribute to hippocampal memory processing under differing behavioral states.

\section{Materials and Methods}

\section{Slice preparation}

Hippocampal slices were prepared as previously described (Grover and Teyler 1994; Holmes and Grover 2006). Briefly, SpragueDawley rats (male, 30-60 d old, Hilltop Lab Animals) were sedated by $\mathrm{CO}_{2}$ /air inhalation, and decapitated. The brain was removed and placed into chilled artificial cerebrospinal fluid (ACSF) composed of $124 \mathrm{mM} \mathrm{NaCl}, 26 \mathrm{mM} \mathrm{NaHCO} 3,3.4 \mathrm{mM} \mathrm{KCl}, 1.2 \mathrm{mM}$ $\mathrm{NaH}_{2} \mathrm{PO}_{4}, 2.0 \mathrm{mM} \mathrm{CaCl}_{2}, 2.0 \mathrm{mM} \mathrm{MgSO}_{4}, 10 \mathrm{mM}$ glucose, $\mathrm{pH} 7.35$, equilibrated with $95 \% \mathrm{O}_{2}, 5 \% \mathrm{CO}_{2}$. The brain was blocked, glued to the stage of a vibrating microtome (Campden Instruments), immersed in chilled ACSF, and sectioned into 400- $\mu \mathrm{m}$-thick coronal slices. Transverse hippocampal slices were dissected free from surrounding structures and stored at room temperature $\left(20^{\circ} \mathrm{C}-22^{\circ} \mathrm{C}\right)$ in an interface holding chamber. Individual slices were transferred as needed to a small volume $(\sim 200 \mu \mathrm{L})$ interface recording chamber $\left(35^{\circ} \mathrm{C}\right.$, perfusion rate $1-1.5 \mathrm{~mL} / \mathrm{min}$ with oxygenated ACSF). A total of 346 slices from 141 animals were used.

\section{Field potential recordings}

Extracellular potentials were recorded through low impedance (3$4 \mathrm{M} \Omega$ ) glass micropipettes filled with ACSF and placed into the stratum radiatum of area CA1. Signals were amplified (gain 100-1000) and filtered $(0.05-3000 \mathrm{~Hz}$, or $0.1-10,000 \mathrm{~Hz})$, then digitized (10-100 kHz; National Instruments) and stored on a personal computer using WinWCP or WinEDR software (Strathclyde Electrophysiology Software, John Dempster, University of Strathclyde). Field potential recordings from 297 slices are included in the data presented here.

\section{Whole-cell recording}

Whole-cell patch clamp recordings $(n=$ 49 cells from 49 slices) were obtained from the somata of CA1 pyramidal neurons by the method of Blanton et al. (1989). Patch electrodes (3-4 M 2 ) were filled with $130 \mathrm{mM}$ potassium gluconate, $10 \mathrm{mM}$ sodium HEPES (N-[2-hydroxyethyl]piperazine- $\mathrm{N}^{\prime}$-[2-ethanesulfonic acid]), $3 \mathrm{mM} \mathrm{MgCl}_{2}$, and $0.2 \%$ neurobiotin, adjusted to $285 \mathrm{mOsm}, \mathrm{pH}$ 7.2. Recordings were done in the continuous current clamp mode of an Axoclamp 2B (Axon Instruments). Signals were amplified (gain 10) and low-pass filtered (3 $\mathrm{kHz})$, then digitized $(10-100 \mathrm{kHz} ; \mathrm{Na}-$ tional Instruments) and stored on a personal computer using the WinWCP or WinEDR programs. Access resistance was 
A

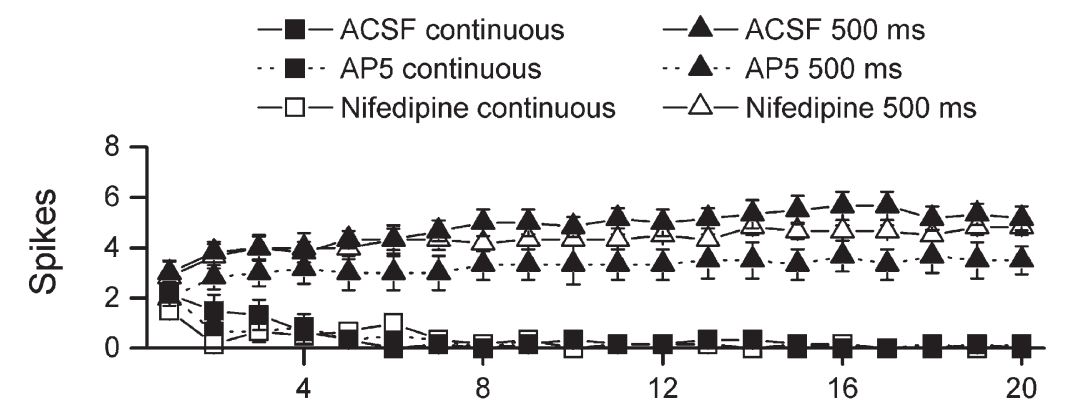

B

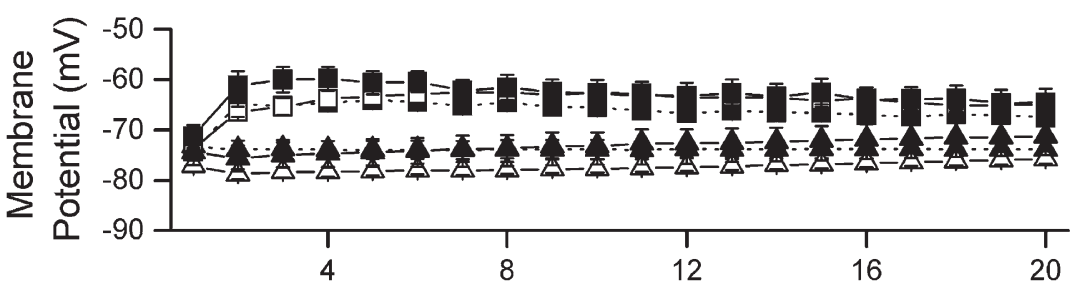

C

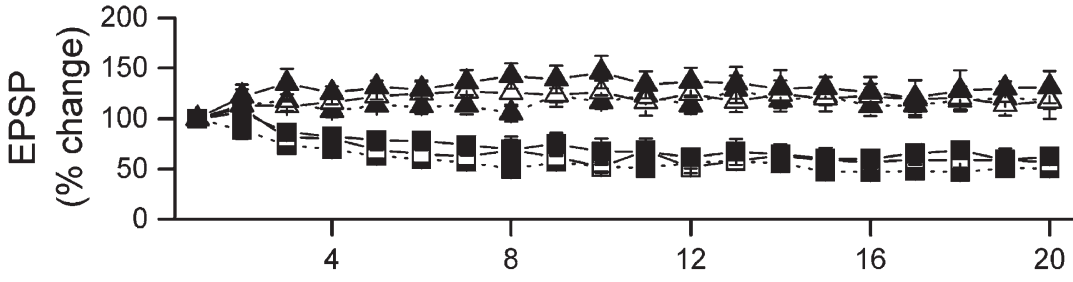

D

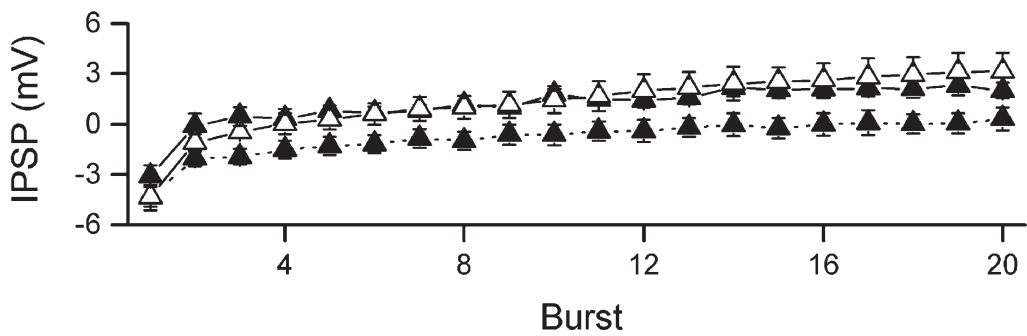

Figure 8. The NMDA receptor antagonist, AP5, altered the postsynaptic response to burst stimulation but did not affect the response during continuous tetanization. The L-type calcium channel antagonist, nifedipine, had no discernible effects on the postsynaptic response during either burst stimulation or continuous tetanization. (A) AP5, but not nifedipine, reduced spike firing during 500 msec interval burst stimulation. Neither AP5 nor nifedipine altered spike firing during continuous $100-$ $\mathrm{Hz}$ tetanization. (B) Membrane potentials measured immediately before each burst were unaffected by AP5 or nifepidine. (C) Facilitation of EPSP slope during 500-msec interval burst stimulation was not altered by AP5 or nifedipine. Depression of EPSP slope during continuous $100-\mathrm{Hz}$ stimulation was also unaffected by AP5 or nifedipine. (D) AP5, but not nifedipine, reduced the rate of decline in post-burst inhibition during 500-msec interval burst stimulation.

measured and compensated using the Axoclamp bridge balance circuitry $(20.8 \pm 1.5 \mathrm{M} \Omega$, mean \pm SEM). Membrane potentials were corrected for a calculated liquid junction potential of $10 \mathrm{mV}$. Cells included in this study had stable resting membrane potentials averaging $-74.23 \pm 0.7 \mathrm{mV}$ (range -64.5 to $-85.9 \mathrm{mV}$ ) and input resistances (determined from the steady state membrane potential change at the end of 100- to 500-msec current steps between -200 and $100 \mathrm{pA}$ ) of $49.2 \pm 1.5 \mathrm{M} \Omega$ (range 31.5-80.5 $\mathrm{M} \Omega$ ). We recorded from cells for a period between 10 and $20 \mathrm{~min}$ before delivery of burst stimulation (see below). During this time cells were stimulated by current injection through the recording electrode (-500-1500 pA, 2-500 msec, minimum 5-sec interval between current steps), and by stimulation of presynaptic afferents (see below).

Neurobiotin-filled cells were visualized using the avidin-biotin complex $(\mathrm{ABC})$ method. Slices were fixed overnight in $4 \%$ paraformaldehyde at $4^{\circ} \mathrm{C}-$ $8^{\circ} \mathrm{C}$. After rinsing with phosphate buffered saline (PBS), slices were incubated in a peroxidase quenching solution for 30 min $\left(1 \% \mathrm{H}_{2} \mathrm{O}_{2}, 10 \%\right.$ methanol in $\mathrm{PBS})$, rinsed, incubated in overnight at $4^{\circ} \mathrm{C}-8^{\circ} \mathrm{C}$ in Vectastain $\mathrm{ABC}$ Elite Reagent (Vector Laboratories) with $0.1 \%$ Triton $\mathrm{X}$ 100 and $0.02 \%$ bovine serum albumin. The next day, slices were rinsed in PBS, incubated in a solution containing diaminobenzidine and urea $\mathrm{H}_{2} \mathrm{O}_{2}$ (SigmaFast, Sigma Aldrich), with $0.06 \% \mathrm{NiCl}(20$ $\mathrm{min})$, rinsed again, cleared in glycerol $(1 \mathrm{~h}$ in $50 \%$ glycerol, $1 \mathrm{~h}$ in $90 \%$ glycerol), mounted in Immu-Mount (Thermo Scientific), coverslipped, and viewed under a microscope. All recovered cells had pyramidal shaped somata contained within stratum pyramidale of area CA1.

\section{Synaptic stimulation}

\section{Test stimulation}

A bipolar stimulating electrode was placed into stratum radiatum in area CA1 500-800 $\mu \mathrm{m}$ from the recording site. Stimuli were delivered as bipolar, constant voltage stimuli (duration 0.1$0.3 \mathrm{msec}$ ). For field potential recordings, stimulus intensity was determined by constructing an input-output curve plotting fEPSP slope against stimulus intensity. Stimulus intensity was chosen as the lowest level of stimulation voltage that evoked a discernible population spike (positive deflection superimposed on the negative field potential). Complete input-output curves were not constructed for whole-cell recordings. Instead, spike threshold was determined by varying stimulus intensity until the voltage needed to evoke a spike on $\sim 50 \%$ of trials was found. Test stimuli were delivered at a rate of $1 / 15$ sec.

\section{Burst stimulation}

We delivered a total of 80 stimuli as either a continuous train at $100-\mathrm{Hz}$ or as 20 discrete bursts of 4 stimuli. Burst intervals examined were 100, 200, 350, and 500 msec, and 1, 5, 10, and 20 sec. Stimuli within bursts were always delivered at 10 -msec intervals $(100 \mathrm{~Hz})$, with stimulus intensity set at spike threshold.

\section{Primed burst stimulation}

A single priming stimulus was delivered either 200 or $500 \mathrm{msec}$ prior to a single burst (4 stimuli at $100 \mathrm{~Hz}$ ). During primed burst stimulation, stimulation intensity was increased from the test level to the level that evoked an EPSP with maximal slope. Immediately following primed burst stimulation, the original test stimulus intensity was restored.

\section{LTP assessment}

A 15-min baseline period preceded attempted LTP induction using one of the burst stimulation intervals described above. Recordings 
were continued for at least $30 \mathrm{~min}$ following LTP induction. LTP was quantified by comparing the mean fEPSP slope over the 25- to 30-min post-tetanus period with the mean fEPSP slope during the baseline period and calculating the percentage change from baseline. The 25- to 30-min post-tetanus period was chosen for assessment of LTP because fEPSPs had reached a stable level of change by this time (see Figs. 1-3 and 5).

\section{Reagents}

Drugs were prepared as concentrated stock solutions. Nifedipine (Sigma) was dissolved in DMSO at a concentration of $20 \mathrm{mM}$; D-AP5 (Acros Organics) was dissolved in $100 \mathrm{mM} \mathrm{NaOH}$ at a concentration of $100 \mathrm{mM}$. Stock solutions were diluted to the final concentration by addition to the ACSF perfusing the tissue. When DMSO was used, the final concentration was $0.1 \%$. Neurobiotin and the Vectastain $\mathrm{ABC}$ Elite Reagent were from Vector Laboratories. Salts and all other reagents were from either Sigma or Fisher.

\section{Data analysis}

Data were collected and initially analyzed using WinWCP or WinEDR software. Additional analysis was performed using Origin (OriginLab), Gnumeric (http://www.gnome.org/projects/gnumeric/), and the $\mathrm{R}$ statistical computing environment (http://www. r-project.org/). Unless otherwise indicated, all values are reported as mean \pm 1 standard error of the mean (SEM). Statistical significance was assessed, as appropriate, by one- or two-tailed $t$-tests, or by analysis of variance (ANOVA) with post-hoc comparisons made using the Tukey HSD test. For all tests of statistical significance, $P<0.05$ was considered significant.

\section{Acknowledgment}

This work was supported by NIAAA grant AA014294 through the CRCNS (Collaborative Research in Computational Neuroscience) Program.

\section{References}

Albensi, B.C., Oliver, D.R., Toupin, J., and Capocchi, G. 2007. Electrical stimulation protocols for hippocampal synaptic plasticity and neuronal hyper-excitability: Are they effective or relevant? Exp. Neurol. 204: $1-13$.

Alger, B.E., Pitler, T.A., Wagner, J.J., Martin, L.A., Morishita, W., Kirov, S.A. and Lenz, R.A. 1996. Retrograde signalling in depolarization-induced suppression of inhibition in rat hipocampal CA1 cells. J. Physiol. 496: 197-209.

Bland, B.H. 1986. The physiology and pharmacology of hippocampal formation theta rhythms. Prog. Neurobiol. 26: 1-54.

Blanton, M.G., Lo Turco, J.J., and Kriegstein, A.R. 1989. Whole cell recording from neurons in slices of reptilian and mammalian cerebral cortex. J. Neurosci. Methods 30: 203-210.

Bliss, T.V. and Collingridge, G.L. 1993. A synaptic model of memory: Longterm potentiation in the hippocampus. Nature 361: 31-39.

Bliss, T.V. and Lomo, T. 1993. Long-lasting potentiation of synaptic transmission in the dentate area of the anaesthetized rabbit following stimulation of the perforant path. J. Physiol. 232: 331-356.

Buzsáki, G. 1986. Hippocampal sharp waves: Their origin and significance. Brain Res. 398: 242-252.

Buzsáki, G. 1989. Two-stage model of memory trace formation: A role for noisy brain states. Neuroscience 31: 551-570.

Buzsáki, G. 2002. Theta oscillations in the hippocampus. Neuron 33: 325-340.

Capocchi, G., Zampolini, M., and Larson, J. 1992. Theta burst stimulation is optimal for induction of LTP at both apical and basal dendritic synapses on hippocampal CA1 neurons. Brain Res. 591: 332-336.

Cavus, I. and Teyler, T. 1996. Two forms of long-term potentiation in area CA1 activate different signal transduction cascades. J. Neurophysiol. 76: 3038-3047.

Collingridge, G.L., Kehl, S.J., and McLennan, H. 1983. Excitatory amino acids in synaptic transmission in the Schaffer collateral-commissural pathway of the rat hippocampus. J. Physiol. 334: 33-46.

Collingridge, G.L., Herron, C.E., and Lester, R.A. 1988. Frequencydependent $N$-methyl-D-aspartate receptor-mediated synaptic transmission in rat hippocampus. J. Physiol. 399: 301-312.
Davies, C.H. and Collingridge, G.L. 1993. The physiological regulation of synaptic inhibition by $\mathrm{GABA}_{\mathrm{B}}$ autoreceptors in rat hippocampus. J. Physiol. 472: 245-265.

Davies, C.H. and Collingridge, G.L. 1996. Regulation of EPSPs by the synaptic activation of $\mathrm{GABA}_{\mathrm{B}}$ autoreceptors in rat hippocampus. J. Physiol. 496: 451-470.

Davies, C.H., Davies, S.N., and Collingridge, G.L. 1990. Paired-pulse depression of monosynaptic GABA-mediated inhibitory postsynaptic responses in rat hippocampus. J. Physiol. 424: 513-531.

Diamond, D.M., Dunwiddie, T.V., and Rose, G.M. 1988. Characteristics of hippocampal primed burst potentiation in vitro and in the awake rat. J. Neurosci. 8: 4079-4088.

Greenstein, Y.J., Pavlides, C., and Winson, J. 1988. Long-term potentiation in the dentate gyrus is preferentially induced at theta rhythm periodicity. Brain Res. 438: 331-334.

Grover, L.M. and Teyler, T.J. 1990. Two components of long-term potentiation induced by different patterns of afferent activation. Nature 347: 477-479.

Grover, L.M. and Teyler, T.J. 1994. Activation of NMDA receptors in hippocampal area CA1 by low- and high-frequency orthodromic stimulation and their contribution to induction of long-term potentiation. Synapse 16: 66-75.

Harris, E.W., Ganong, A.H., and Cotman, C.W. 1984. Long-term potentiation in the hippocampus involves activation of $N$-methylD-aspartate receptors. Brain Res. 323: 132-137.

Herron, C.E., Lester, R.A., Coan, E.J., and Collingridge, G.L. 1986. Frequency-dependent involvement of NMDA receptors in the hippocampus: A novel synaptic mechanism. Nature 322: 265-268.

Hessler, N.A., Shirke, A.M., and Malinow, R. 1993. The probability of transmitter release at a mammalian central synapse. Nature $\mathbf{3 6 6}$ : 569-572.

Holmes, W.R. 2000. Models of calmodulin trapping and CaM kinase II activation in a dendritic spine. J. Comput. Neurosci. 8: 65-85.

Holmes, W.R. and Grover, L.M. 2006. Quantifying the magnitude of changes in synaptic level parameters with long-term potentiation. J. Neurophysiol. 96: 1478-1491.

Jensen, K., Lambert, J.D., and Jensen, M.S. 1999. Activity-dependent depression of GABAergic IPSCs in cultured hippocampal neurons. J. Neurophysiol. 82: 42-49.

Kraushaar, U. and Jonas, P. 2000. Efficacy and stability of quantal GABA release at a hippocampal interneuron-principal neuron synapse. $J$. Neuroscience 20: 5594-5607.

Lambert, N.A. and Wilson, W.A. 1994. Temporally distinct mechanisms of use-dependent depression at inhibitory synapses in the rat hippocampus in vitro. J. Neurophysiol. 72: 121-130.

Larson, J. and Lynch, G. 1986. Induction of synaptic potentiation in hippocampus by patterned stimulation involves two events. Science 232: 985-988.

Larson, J. and Lynch, G. 1988. Role of $N$-methyl-D-aspartate receptors in the induction of synaptic potentiation by burst stimulation patterned after the hippocampal theta-rhythm. Brain Res. 441: 111-118.

Larson, J. and Lynch, G. 1989. Theta pattern stimulation and the induction of LTP: The sequence in which synapses are stimulated determines the degree to which they potentiate. Brain Res. 489: 49-58.

Larson, J., Wong, D., and Lynch, G. 1986. Patterned stimulation at the theta frequency is optimal for the induction of hippocampal long-term potentiation. Brain Res. 368: 347-350.

Lynch, M.A. 2004. Long-term potentiation and memory. Physiol. Rev. 84: 87-136.

Morgan, S.L. and Teyler, T.J. 1999. VDCCs and NMDARs underlie two forms of LTP in CA1 hippocampus in vivo. J. Neurophysiol. 82: 736-740.

Moroni, F., Nobili, L., Curcio, G., De Carli, F., Fratello, F., Marzano, C., De Gennaro, L., Ferrillo, F., Cossu, M., Francione, S., et al. 2007. Sleep in the human hippocampus: A stereo-EEG study. PloS ONE 2(9): e867. doi: 10.1371/journal.pone.0000867.

Morris, R.G.M. 2003. Long-term potentiation and memory. Philos. Trans. R. Soc. Lond. B Biol. Sci. 358: 643-647.

Morrisett, R.A., Mott, D.D., Lewis, D.V., Swartzwelder, H.S., and Wilson, W.A. 1991. $\mathrm{GABA}_{\mathrm{B}}$-receptor-mediated inhibition of the $N$-methyl-Daspartate component of synaptic transmission in the rat hippocampus. J. Neurosci. 11: 203-209.

Mott, D.D., Xie, C.W., Wilson, W.A., Swartzwelder, H.S., and Lewis, D.V. 1993. GABA $\mathrm{B}$ autoreceptors mediate activity-dependent disinhibition and enhance signal transmission in the dentate gyrus. J. Neurophysiol. 69: 674-691.

Nguyen, P.V. and Kandel, E.R. 1997. Brief theta-burst stimulation induces a transcription-dependent late phase of LTP requiring cAMP in area CA1 of the mouse hippocampus. Learn. Mem. 4: 230-243.

Olpe, H.R., Steinmann, M.W., Greiner, K., and Pozza, M.F. 1994. Contribution of presynaptic GABA-B receptors to paired-pulse depression of GABA-responses in the hippocampus. Naunyn Schmiedebergs Arch. Pharmacol. 349: 473-477. 
Pacelli, G.J., Su, W., and Kelso, S.R. 1989. Activity-induced depression of synaptic inhibition during LTP-inducing patterned stimulation. Brain Res. 486: $26-32$.

Pennartz, C.M.A., Uylings, H.B.M., Barnes, C.A., and McNaughton, B.I. 2002. Memory reactivation and consolidation during sleep: From cellular mechanisms to human performance. Prog. Brain Res. 138: 143166.

Reich, C.G., Karson, M.A., Karnup, S.V., Jones, L.M., and Alger, B.E. 2005. Regulation of IPSP theta rhythm by muscarinic receptors and endocannabinoids in hippocampus. J. Neurophysiol. 94: 4290-4299.

Rose, G.M. and Dunwiddie, T.V. 1986. Induction of hippocampal long-term potentiation using physiologically patterned stimulation. Neurosci. Lett. 69: 244-248.

Staubli, U. and Lynch, G. 1987. Stable hippocampal long-term potentiation elicited by "theta" pattern stimulation. Brain Res. 435: 227-234.

Stevens, C.F. and Wang, Y. 1995. Facilitation and depression at single central synapses. Neuron 14: 795-802.

Suzuki, S.S. and Smith, G.K. 1987. Spontaneous EEG spikes in the normal hippocampus. I. Behavioral correlates, laminar profiles and bilateral synchrony. Electroencephalogr. Clin. Neurophysiol. 67: 348-359.

Thompson, S.M. and Gähwiler, B.H. 1989a. Activity-dependent disinhibition. I. Repetitive stimulation reduces IPSP driving force and conductance in the hippocampus in vitro. J. Neurophysiol. 61: 501511.

Thompson, S.M. and Gähwiler, B.H. 1989b. Activity-dependent disinhibition. II. Effects of extracellular potassium, furosemide, and membrane potential on $\mathrm{E}_{\mathrm{Cl}}{ }^{-}$in hippocampal CA3 neurons. $J$. Neurophysiol. 61: 512-523.

Thompson, S.M. and Gähwiler, B.H. 1989c. Activity-dependent disinhibition. III. Desensitization and $\mathrm{GABA}_{\mathrm{B}}$ receptor-mediated presynaptic inhibition in the hippocampus in vitro. J. Neurophysiol. 61: 524-533.

Vanderwolf, C.H. 1969. Hippocampal electrical activity and voluntary movement in the rat. Electroencephalogr. Clin. Neurophysiol. 26: 407-418.

Whishaw, I.Q. and Vanderwolf, C.H. 1973. Hippocampal EEG and behavior: Changes in amplitude and frequency of RSA (theta rhythm) associated with spontaneous and learned movement patterns in rats and cats. Behav. Biol. 8: 461-484.

Wolansky, T., Clement, E.A., Peters, S.R., Palczak, M.A., and Dickson, C.T. 2006. Hippocampal slow oscillation: A novel EEG state and its coordination with ongoing neocortical activity. J. Neurosci. 26: 62136229.

Received August 8, 2008; accepted in revised form October 23, 2008. 


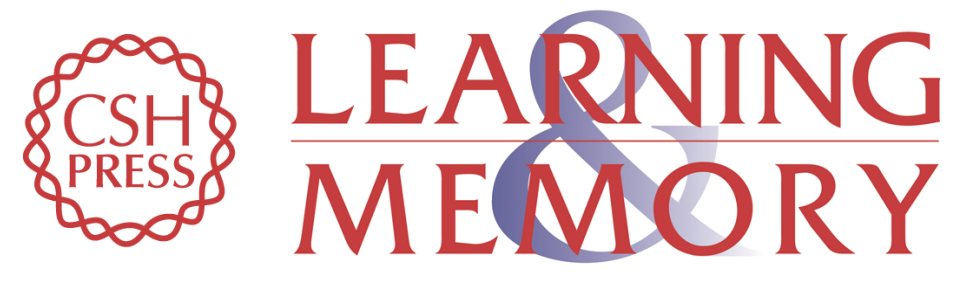

\section{LTP in hippocampal area CA1 is induced by burst stimulation over a broad frequency range centered around delta}

Lawrence M. Grover, Eunyoung Kim, Jennifer D. Cooke, et al.

Learn. Mem. 2009, 16:

Access the most recent version at doi:10.1101//m.1179109

References This article cites 53 articles, 6 of which can be accessed free at:

http://learnmem.cshlp.org/content/16/1/69.full.html\#ref-list-1

License

Email Alerting Receive free email alerts when new articles cite this article - sign up in the box at the Service top right corner of the article or click here. 